\title{
The Impact of the Dental Profession on the Health Status of a Sample of Iraqi Dentists
}

\author{
Jamal N. Ahmed \\ BDS, MS, PhD - Department of oral diagnosis/Baghdad college of Dentistry. \\ Nada A. Mousa \\ MBCHB, MSc, PhD - Public health directorate/Iraqi Ministry of Health.
}

\begin{abstract}
Background Dental practitioners as other healthcare workers confront an identified risk of occupational complications. This profession has been practiced in Iraq for decades. Baghdad college of dentistry was established in the middle of the past century and graduated a significant number of dentists. Nearly ten thousands dentists have been registered in the Iraqi dental association, therefore the purpose of this study was to identify the occupational risks and the impact of the dental profession on the health of a sample of Iraqi dentists.

Material and method Information was obtained using a self-report questionnaire form designed for this purpose and distributed to dentists who agreed to take part in this survey. The respondents for this study included all dentists working in the government institutions in Baghdad (the capital) and the other provinces of Iraq and private practices as well. The data were collected and analyzed to explore the frequency of the occupational hazards (diseases) by the authors.

Results The total number of the dentists responded to the survey were (284) which represent $81 \%$ of the respondent. The male to female ratio 1.39:1. Their age ranged between 23 - 64 years and the mean was 37.1 with SD \pm 9.6. The average weekly working days was (5), with average working hours of (37.5). Dentistry was considered by $92.7 \%$ as a stressful occupation with $64 \%$ was classified it moderate level. The frequency of the musculoskeletal problems was $54.9 \%$ followed by joint $50.51 \%$, vision $45.7 \%$. cardiovascular $23.23 \%$, allergy $17.6 \%$, neural symptoms related to the practice $17.34 \%$.and $9.8 \%$ infections transmitted through the occupation.

Conclusion The majority of dentists feel that dentistry is a stressful profession. The occupation related problems were mainly noticed as musculoskeletal followed by joint, visual, cardiovascular, neural, allergy and infectious diseases respectively. Identifying and focusing on the risks of the occupation in the Iraqi dental colleges curriculums and the Iraqi dental association continuing education programs for the graduated dentists is strongly recommended.
\end{abstract}

\section{KEYWORDS}

Dental profession, occupational hazards, dental health status

\section{CITE THIS ARTCLE:}

Ahmed J, Mousa N. The Impact of the Dental Profession on the Health Status of a Sample of Iraqi Dentists. Iraqi Dent. J. 2015; 37(3):107-113. http://www.iraqidentaljournal.com

$$
\text { تأثير مهنة طب الاسنان على الحالة الصحية لعينة من اطباء الاسنان العراقيين }
$$

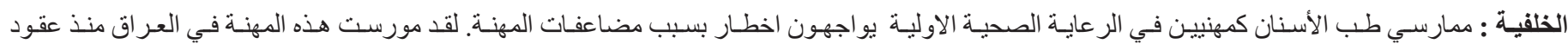

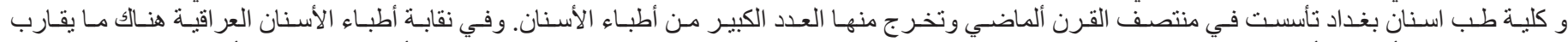

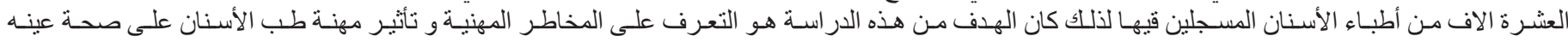

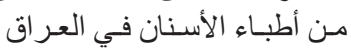

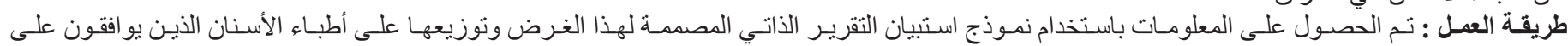

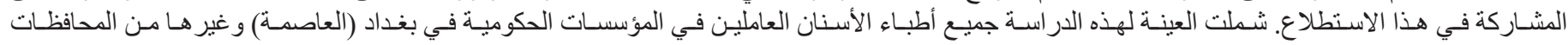

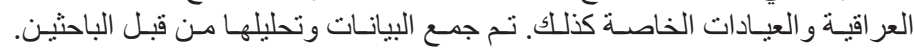

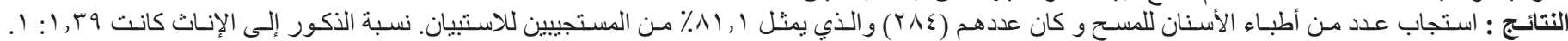

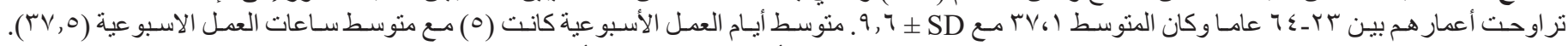

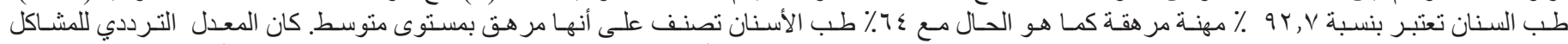

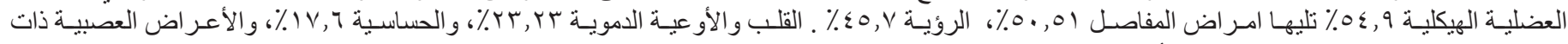

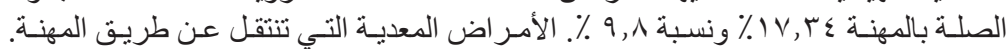

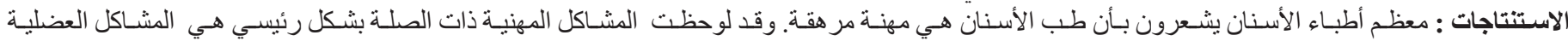

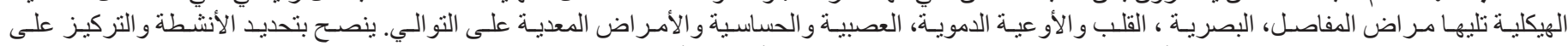

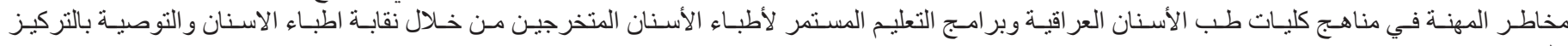

\section{INTRODUCTION}

Despite the numerous advances in dental technologies, dentistry is still considered by the practitioners and most of the public as being a hazardous occupation. Many risk factors or hazards are still persistent in modern dentistry. They vary from mild and easy or self curable, as influenza and mental fatigue, to more serious and incurable as hepatitis and $\operatorname{AIDS}^{(1,2)}$.

The source of risk factors involved in the dental occupation are mainly classified as, Physical, ergonomic, chemical and biological hazards. Most 


\section{Oral Diagnosis}

potential sources for occupational hazards to dentists are working for long periods of time in physiologically improper positions, contact with patients, exposure to certain chemicals and materials used in dental practice, handling sharp dental instruments and accessories, contact with X-ray, sound noise at different sound levels, in addition to, dealing with different personalities. ${ }^{(3,4,5,6)}$ Physical and ergonomic hazards commonly include low back pain, neck and shoulder complaints, hand arm vibration syndrome and other Musculoskeletal complications. They have direct relation to dentistry procedure, like postural situations that may increase the risk of twisting and contouring the body to perform the treatment, ${ }^{(7)}$ in addition, intensity and reflection of light may also have an impact on the postural position and visual acuity as well.

Psychological and Stress are hazards that have direct effect on the health status of the dentist. It is considered the leading cause to emotional exhaustion and depersonalization. Some evidences suggest that dentists suffer a high level of job-related stressors. (8,9) Dentists indicated running behind schedule, heavy work load, dealing with uncooperative and anxious patients, identification and management of pain, challenges to achieve technical perfection are considered the most intense stressors in their work $(10,11)$

Dental practitioners as other healthcare workers confront an identified risk of biological complication. The direct contact with patients, small operating field, the variety of sharp instruments used in dental procedure and frequent patient movement may expose the dentist to blood-borne pathogens. Needles and other sharp objects, spatter, and aerosols can transmit serious and life-threatening infections. Therefore blood borne pathogens standard legislation designed to reduce worker exposure to blood borne pathogens such as HIV and HBV became law. ${ }^{(12)}$ Mechanisms in occupational hand dermatitis is of particular problem to the dental personnel. The skin shows redness itchy rash that may hamper the daily practice. Risk of allergic reactions is mainly caused by gloves containing latex, furthermore, allergic skin irritation could also be caused by using rubber dam, detergents, disinfectants, solvents, lubricating oils, $\mathrm{X}$-ray processing chemicals and many more dental materials $^{(13,14)}$

Eye problem is a fairly common complains among the general population, however there is no doubt aggravated by working in a narrow and dark field cavity, bright reflection of dental light and other dental procedures such as light cure. ${ }^{(15)}$

As new technologies and materials are introduced to the profession, other adverse health risks arise, once identified and recognized as a risk, new guidelines, precautions and protocols should be rapidly instituted to greatly reduce or even eliminate the occupational hazard. The significant issues have to be considered and continuous educational program introduced to the students and professionals as well.

This profession has been practiced in Iraq for decades. Baghdad dental school established in the middle of the past century and graduated a significant number of dentists. Nearly ten thousand dentists have been registered in the Iraqi dental association, therefore the purpose of this study was to identify the occupational risks and the impact of the dental profession on the health of the dentists in Iraq.

\section{SUBJECTS, MATERIAL AND METHODS}

Approvals were obtained from the authorities to conduct this study. Information was obtained using a self-report questionnaire form designed for this purpose and distributed to dentists who agreed to take part in this survey. The respondents for this study included all the dentists working in the government institutions in Baghdad (the capital) and the other provinces of Iraq. The dental health care to the public is provided mainly through government setup (Government Dental Colleges and Hospitals, Primary and specialized Dental Health care Centers), in addition to private colleges and dentists who own their private practices. The dentists in these institutions, in addition to the workdays (between 8:30am-2:30pm), have the authority to own an afternoon private practice (between 4:0pm-8:0pm) according to the Iraqi legislations. The data collected were assessed and analyzed to elucidate the incidence and frequency distribution of the risk factors and the health status of the dentists in Iraq.

\section{RESULTS}

The total number of the dentists responded to the survey were (284) out of 350 questionnaire form distributed which represent $81 \%$ of the respondent. They were ( 166 ) males and ( 118 ) females with male to female ratio 1.39:1. Their age ranged between 23 - 64 years and the mean was 37.1 with $\mathrm{SD} \pm$ 9.6. Among those, there were (164) general practioners (GP) and (120) specialists. The years of service in dentistry ranged between $1-42$ years with a mean of 14.060 and $\mathrm{SD} \pm 9.552$. The working hours were averaged (4.3) am and (3.2) pm daily in the dental 
clinics. The average weekly working days was (5) with average working hours of (37.5). The dentists who take annual leaves from their private practice were $(33 \%)$.

There was no significant difference of the studied dental occupation hazards between the two genders.

The dentists who feel that dentistry is a stressful occupation was $92.7 \%$. The degree of stress were varied between mild $14 \%$, moderate $64 \%$ and sever $22 \%$. It has been found that $91 \%$ aware and concerned that this profession has a serious impact on the dentist's health, and $60 \%$ considered offering comfortable workplace and watch their posture during practice.

One of the high prevalent issue of the health status observed in this study was the musculoskeletal problem. The frequency of the vertebral column problems among the total number responded to this survey was $54.9 \%$. Vertebral Disc problems (diagnosed discopathy) was found in $19.2 \%$, cervical pain $46.8 \%$ and lumbar pain $44.2 \%$. Among those sufferers, the dentists who think that their problems was due to the profession was $78.8 \%$.

The dentists who have joints problems and their complain as they think due to the profession were $47.3 \%$. The participants reported one or more of the problems and were categorized in the knee $26.8 \%$, Shoulder $17.52 \%$ wrists and fingers $26.7 \%$.
Those who suffer from visual problems and wearing eye glasses during dental practice were $45.7 \%$. The dentists who feel eye strain due to profession were $23.2 \%$.

The cardiovascular symptoms or diseases were present in $23.23 \%$ of the dentists. The male and female result was $26.5 \%$ and $18.64 \%$ respectively. The stress related symptoms was classified as hypertension, palpitation and angina.

There was $17.6 \%$ of the respondent having signs and symptoms of allergy from one or more of materials used in the dental practice. It was classified as dermatitis from latex $3.87 \%$, chemical materials used in dental practice (dental materials, anesthesia, detergent, disinfectants and $\mathrm{x}$ ray chemicals) $11.69 \%$ and respiratory or sinus allergy $2.1 \%$.

The neural symptoms related to the practice was about $17.34 \%$. these symptoms were pain and numbness of the nerves which mainly involves the hands.

The infectious diseases affecting $9.8 \%$ of the dentist who think were transferred due to the profession.

It was found that $94 \%$ were using one or more of the protective barriers during dental work. All the required measures for the cross infection control (gloves, masks, eye protection or goggles, gowns) were considered by only $27 \%$ of the respondent.

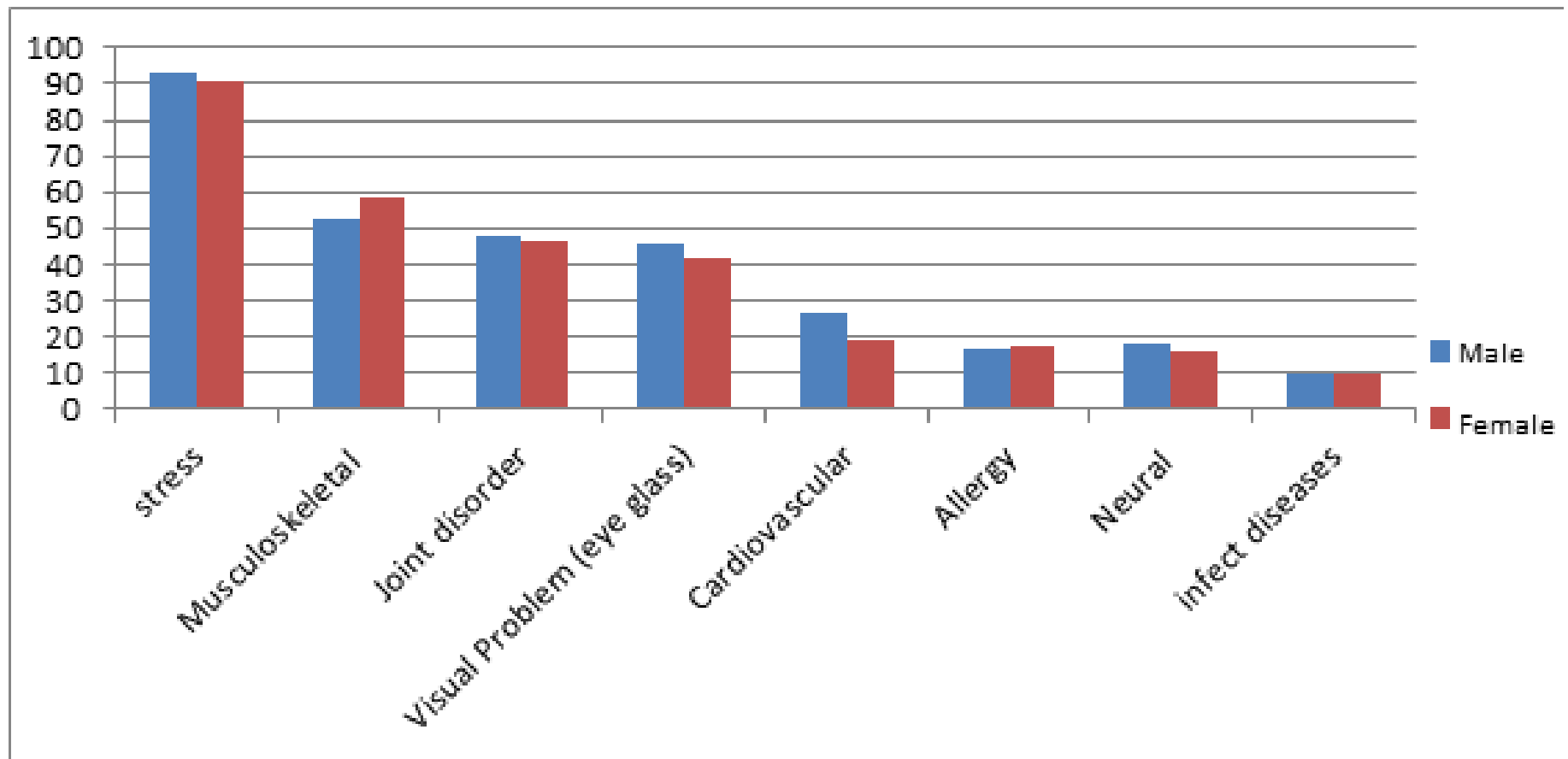

Figure 1. The frequency of occupation related diseases in regard to gender.. 


\section{Oral Diagnosis}

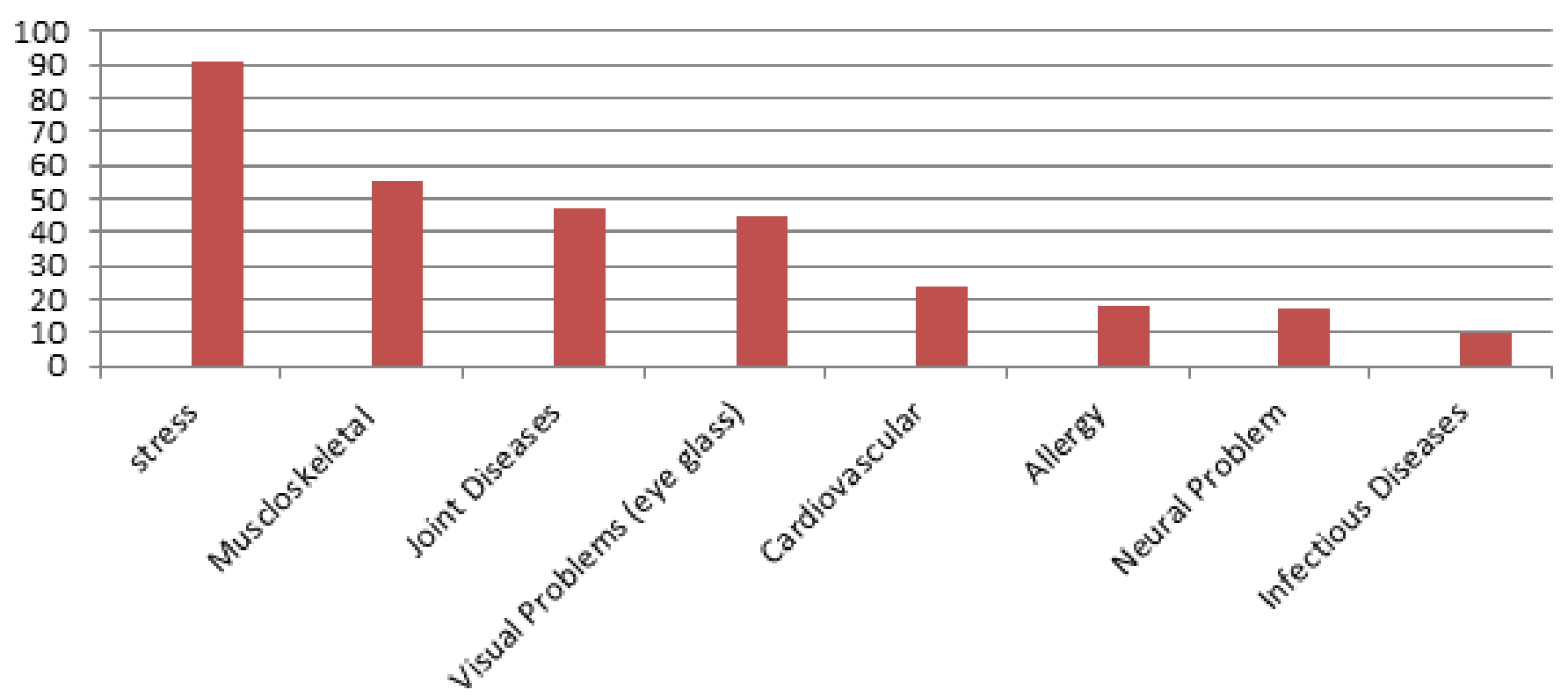

Figure 2. The frequency of the occupation related diseases.

\section{DISCUSSION}

Dentistry in Iraq is considered relatively an old profession and practiced earlier during the past century if compared to that of the countries of the Middle East. Baghdad College of dentistry is considered pioneer in this region, it was established in the early 50 's of the last century and a significant number of general practitioners and dental specialists have been graduated from this college. The dental services in this country are introduced to the public in the governmental clinics and private practices as well. All the graduates are hired in the governmental specialized clinics for one year training after graduation and then serve in district cities, afterword legally. They are eligible to have their own afternoon private practice besides keeping the job in the governmental morning public service institutions.

Many reports have mentioned the hazards of this occupation; therefore it is worth to survey the impact of dentistry on the health of the dentists in Iraq.

The male to female ratio of the dentists responded to the survey was $1.39: 1$. This variation may be because the males in the distant provinces who volunteered to participate were more and keen to deliver the questionnaire forms.

It has been noticed that the morning and afternoon hours refer to the effort of the working hours. and the average weekly working hours is relatively in the similar average of that of the other studies ${ }^{(16)}$.

Only one third of the dentists take regular annual leave. This could be explained that the dentists in Iraq consider their income is less than their colleagues in other countries, in addition they earn low compared to the value of the services they deliver in order to cope with the business demands and the cost of good standard of living.

Many reported studies implicate that dentists perceive their profession as more stressful than other jobs. ${ }^{(17,18)}$ In this study it was noticed that $92.7 \%$ of the respondents feel that practicing their job is stressful and the majority categorized it in a moderate level of stress. The reasons are in addition to the mentioned costs, significant number of the dentists in Iraq work in two different places (governmental and private practices), the crowding and heavy workloads in the morning hours without getting adequate breaks between patient's treatments, compliance of the patients to the schedule, availability of the suitable dental tools to achieve perfection in delivering treatment., moreover the stressful environment and availability of the accessory services in the country.

The static and awkward posture and work practices cause musculoskeletal problems with a significant burden on the dental profession. It starts at the time the dentist starts his professional studies and continues throughout his daily professional practice. Many studies focused on the musculoskeletal symptoms as an existing hazard of dentistry. The cervical and lumbar vertebrae are commonly affected since these are the dynamic regions of the spine. The frequency of musculoskeletal disorder(MDS) (varying from pain or spasm to arthritis and discopathy) in this study was found $54.9 \%$ and expressed as a low back pain. This finding is similar to the Queensland survey which reported that $54 \%$ of dentists suffer from low back pain in a one year survey. ${ }^{(19)}$ and $53 \%$ of the American military dentists had the symptoms, ${ }^{(20)}$ this percentage was also close to a study conducted on 
960 of the American dental society members which reported $57 \%$ of the dentists suffer from occasional back pain. ${ }^{(21)}$ However a higher rate of MSD was found in a Saudi study $74 \%{ }^{(22)}$ and New South Wales Australia $82 \%$. ${ }^{(23)}$ The frequency of this disorder was varied according to the site of the complain Danish survey found $65 \%$ of dentists suffer from shoulder/ neck pain ${ }^{(24)}$, Queensland of 12 month period survey showed $58 \%$ of neck related pain, however Israeli study reported lower rate $(38 \%)$ of dentists suffer from neck pain. ${ }^{(25)}$ In this study, the cervical pain was found in $46.8 \%$ of the respondents. In spite of the close similarity in the frequency of low back and cervical pain, some of the respondents included complained of multiple symptoms. The posture and repetitive movements of the body in standing and sitting close to the patient eventually lead to spine and hand stress, therefore, degenerative changes and discopathy of the spine are the consequence of the chronic exposure to this condition. Severe cervical and lumber pain due to discopathy may hamper the dental professional from practicing his/her occupation. The diagnosed vertebral discopathy was found in $19.2 \%$. The higher prevalent complication was found in the lumbar region followed by the cervical region and one reported case by the participant was in the thoracic region. Musculoskeletal disorder could be a community problem, however the complication due to the dental occupation was expressed in the majority $(78.8 \%)$ of the respondents who declared that it arose due to the profession.

Many studies reported that dentists have an increased risk for cervical spondylosis and for shoulder joint osteoarthrosis. ${ }^{(26)}$ The dentists was also found to have a higher incidence of pain in the first through the third fingers of the right hand compared with the teachers. ${ }^{(27)}$ The dental work requires repetitive hand and joint movements. The associations has been noted between right hand joint and muscle pain and suggest that highly repetitive shoulder muscle contractions, static contractions, and work at shoulder level are hazardous exposure factors. ${ }^{(26)}$ A high frequency (47.3\%) of joint problems among dentist has been noticed in this study. This finding is relatively in consistent with reported health examination in 131 professionally active dentists which found that $42 \%$ of dentists involved had experienced pain and disability or interference with daily activities by neck-shoulder problems. ${ }^{(28)}$

Although eye problems are commonly seen in the general community, the author found worthwhile to include it in the survey. Limited and dark area of working field, tiny anatomical accessed in the procedures, reflection of light, new technologies introduced to the profession (light cure and lasers) are all factors that may affect the acuity or strain the eyes of the dentist or aggravate the dental profession, in addition, few studies are published considering this field. This survey has found that those who suffer from visual problems and wearing medical eye glasses during dental practice were $41.9 \%$ and the dentists who feel eye strain due to profession were noticed in $23.2 \%$ of the participants.

The cardiovascular diseases including hypertension, palpitation, angina, infarction and heart failure were reported by only $23.23 \%$

(male $26.5 \%$ and female $18.64 \%$ ) of the participants. and this finding is in consistent with the WHO estimation of the prevalence of cardiovascular disease in Iraq 24.4\% (male 25.5\% and female 23.3\%). (29) Since there was little information regarding the relation of the dental occupation to cardiovascular diseases, therefore the results would not conclude relation of the risk to the occupation.

Reduced hand function is a consequence due to numbness, muscle weakness, and pain which later cause restricted abilities to perform activities at work. Pain in the wrist of the hands and numbness were the common symptoms associated while practicing dental treatment, which the sufferers varied in their complaint from headache, carpal tunnel syndrome of the upper extremity which reported may be due to profession $^{(30,31)}$, pain of the hands and numbness of the fingers and weakness of the muscles were found with no significant gender difference. Neural symptoms was found in $17.34 \%$ of the respondents in this study.

Allergy to a wide variety of chemicals used in the dental clinic is one of the common problem among the dental personnel. It is essential that all dental materials are biocompatible and safe for the patient and the dentist, however some base, catalysts, volatile materials detergents and latex may precipitate contact or respiratory allergic reactions. Contact and atopic dermatosis are the two common forms of skin allergy while conjunctivitis and asthma are the ocular and respiratory hypersensitivity observed in this survey. Many studies reported the prevalence of the hypersensitivity to dental materials. The prevalence of dentists suffering from contact dermatitis in New Zealand ${ }^{(32)}$ and $\mathrm{UK}^{(33)}$ was one third of the respondent. while Thailand survey showed about one-fifth (22\%) of dentists complain of the symptoms, ${ }^{(34)}$ however this survey showed lower prevalence $(17.6 \%)$ compared to the mentioned studies. It was observed that the 
majority of the respondents were complaining of skin dermatitis and eczema of the hand due to chemicals and /or detergents followed by latex irritation and the least were having respiratory and sinus allergy which was also noticed among dentists in published studies. ${ }^{(35)}$ These results were in consistent with studies which reported that latex allergy has a low prevalence rate of dermatitis among the health worker personnel. ${ }^{(36,37)}$

Dentists are always in continuous contact with contaminants while practicing the occupation. In spite of the technology and modern dentistry, dental staff are still considered as risk group exposed to infectious diseases. The protective measures and cross infection control adopted by the dentists reduce but not prevent transmission of infection. The prevalence of infections among dentists in Belgium was $9 \%$. (38) Percutaneous injuries comprises more than $50 \%$ of the injuries reported in a study of hospital dental personnel in Bristol. ${ }^{(39)}$ As already cited, the most common sharps injuries among dentists continue to rise from needles and drilling instruments. ${ }^{(40)}$ The results of this investigation showed $9.8 \%$ of the dentists had infectious disease transmitted through the occupation. Various infectious diseases including viruses, bacteria and fungi are potentially transmitted during dental procedure since these agents are present in saliva, blood and expired air of infected individuals. ${ }^{(41,42,43,44)}$ The highest frequency of the diseases observed in this study was influenza followed by pneumonia, hepatitis, herpes labialis and chicken pox respectively. There were two serious infectious diseases reported by the respondents; one case was TB and the other was diphtheria which the respondents think transferred through the occupation.

In this survey it was noticed that the majority of dentists who participated feel that the dental occupation is stressful. The occupation related diseases were mainly noticed as musculoskeletal followed by joint, visual, cardiovascular, neural problems, allergy and infectious diseases respectively. Wearing protective eyewear was the least employed cross infection control measure considered by the dentists and this result has been noticed consistent with other study. (45) The enforcement of strict cross infection control measures and the need for hepatitis $B$ vaccinations for all members of the staff should be emphasized. The physical activities and body positions that predispose workers to backaches were identified and staff education on the prevention of backaches should be provided.

Reviewing the impact of dental profession on the health status of the dentists elucidate the common health problems that might happen to them. Therefore it is recommended that dental curriculum in the Iraqi dental colleges should introduce lectures clarifying the risk factors and the health problems that could occur due to the dental occupation, in addition to the protective measures that are required to avoid these risks. Furthermore the Iraqi dental association requires to introduce the continuing education programs in this field to the graduated dentists.

Advising to avoid stressful dental environment by using the available facilities and the distracting methods such as audiovisual and other devices in practicing dental profession is highly preferred.

\section{REFERENCES}

1. Cleveland JL, Cardo DM. Occupational exposures to human immunodeficiency virus, hepatitis B virus, and hepatitis C virus: risk, prevention, and management. Dent Clin North Am. 2003 Oct;47(4):681-96

2. Ayatollahi J. Needle-stick injuries in a general hospital: Continuing risk and under reporting. Ann Iranian Med. 2006;3:47-50.

3. Gupta A, Ankola AV, Hebbal M Optimizing human factors in dentistry. Dent Res J (Isfahan). 2013 Mar;10(2):254-9.

4. Gurbuz MK, Çatli T, Cingi C, Yaz A, Bal C. Occupational safety threats among dental personnel and related risk factors. J Craniofac Surg. 2013 Nov;24(6):e599-602.

5. Leggat PA, Kedjarune U. Bacterial aerosols in the dental clinic: A review. Int Dent J. 2001;51:39-44.

6. Halboub ES, Barngkgei I, Alsabbagh O, Hamadah O. Radiation-induced thumbs carcinoma due to practicing dental X-ray. Contemp Clin Dent. 2015 JanMar;6(1):116-8.

7. Rundcrantz BL, Johnsson B, Moritz U. Pain and discomfort in the musculoskeletal system among dentists. A prospective study. SwedDentJ. 1991;15:219-28.

8. Myers HL, Myers LB. 'It's difficult being a dentist': Stress and health in the general dental practitioner. $\mathrm{Br}$ Dent J. 2004;197:89-93. discussion 83; quiz 100-1.

9. Rees DW. Work-related stress in health service employees. J Managerial Psychol. 1995;10:4-11

10. Moore R, Brodsgaard I. Dentists' perceived stress and its relation to perceptions about anxious patients. Community Dent Oral Epidemiol. 2001;29:73-80.

11. Roger EA. Stress-related suicide by dentists and other health care workers. JAmDentAssoc.2001;132:786-94.

12. Ferdinand M. OSHA's bloodborne pathogens standard: enforcement, compliance and comment. . J Healthc Mater Manage. 1993 Sep;11(8):12, 14, 16 passim.

13. Rubel DM, Watchorn RB. Allergic contact dermatitis in dentistry. Aust J Dermatol. 2000;41:63-9.

14. Jacobsen N, Aasenden R, Hensten-Pettersen A. Occupational health complaints and adverse patient reactions as perceived by personnel in public dentistry. Community Dent Oral Epidemiol.1991 Jun;19(3):155-9.

15. Bruzell Roll EM, Jacobson N, Hensten-Pettersen A. Health hazards associated with curing light in the dental clinic. Clin Oral Investig. 2004;8:113-7.

16. Health \& Social Care Information Centre Dental Working Hours, England and Wales - 2010-11 and 2011-12. http:// 
www.hscic.gov.uk/catalogue/PUB07140

17. Rodríguez Vázquez LM, Rubiños López E, Varela Centelles A, Blanco Otero AI, Varela Otero F, Varela Centelles P. Stress amongst primary dental care patients. Med Oral Patol Oral Cir Bucal. 2008 Apr 1;13:E253-6.

18. Winwood PC, Winefield AH, Lushington K. The role of occupational stress in the maladaptive use of alcohol by dentists: A study of South Australian general dental practitioners. Aust Dent J. 2003;48:102-9.

19. Leggat PA, Smith DR. Musculoskeletal disorders selfreported by dentists in Queensland, Australia. Aust Dent J. 2006 Dec;51(4):324-7.

20. Jacobsen N, Hensten-Pettersen A. Occupational health problems among dental hygienists. Community Dent Oral Epidemiol. 1995 Jun;23(3):177-81.

21. Leggat PA, Smith DR. Prevalence of hand dermatoses related to latex exposure amongst dentists in Queensland, Australia. Int Dent J. 2006 Jun;56(3):154-8.

22. Al Wazzan KA, Almas K, Al Shethri SE, Al-Qahtani MQ, Back \& neck problems among dentists and dental auxiliaries. J Contemp Dent Pract. 2001 Aug 15;2(3):1730 .

23. Marshall ED, Duncombe LM, Robinson RQ, Kilbreath SL. Musculoskeletal symptoms in New South Wales dentists. Aust Dent J. 1997 Aug;42(4):240-6.

24. Finsen L, Christensen H, Bakke M. Musculoskeletal disorders among dentists and variation in dental work. Appl Ergon.1998 Apr;29(2):119-25.

25. Ratzon NZ, Yaros T, Mizlik A, Kanner T. Musculoskeletal symptoms among dentists in relation to work posture. Work. 2000;15(3):153-158.

26. Hagberg M, Wegman DH. Prevalence rates and odds ratios of shoulder-neck diseases in different occupational groups. Br J Ind Med. 1987 Sep;44(9):602-10.

27. Ding H, Solovieva S, Leino-Arjas $P$, Determinants of incident and persistent finger joint pain during a five-year followup among female dentists and teachers. Arthritis Care Res (Hoboken). 2011 May;63(5):702-10. doi: 10.1002/acr.20437.

28. Lehto TU, Helenius HY, Alaranta HT Musculoskeletal symptoms of dentists assessed by a multidisciplinary approach. Community Dent Oral Epidemiol. 1991 Feb;19(1):38-44.

29. WHO - non communicable diseases (NCD) country profiles, 2014.

30. Cranford CS, Ho JY, Kalainov DM, Hartigan BJ Carpal tunnel syndrome. Am Acad Orthop Surg. 2007 Sep;15(9):537-48.

31. Borhan Haghighi A, Khosropanah H, Vahidnia F, Esmailzadeh S, Emami Z. Association of dental practice as a risk factor in the development of carpal tunnel syndrome. 26. J Dent (Shiraz).2013 Mar;14(1):37-40.

32. Sinclair NA, Thomson WM Prevalence of self-reported hand dermatoses in New Zealand dentists. N Z Dent J. 2004 Jun;100(2):38-41.

33. Burke FJ, Wilson NH, Cheung SW. Factors associated with skin irritation of the hands experienced by general dental practitioners. Contact Dermatitis. 1995 Jan;32(1):35-8.

34. Jainkittivong A, Langlais RP. Herpes B virus infection. Oral Surg Oral Med Oral Pathol Oral Radiol Endod. 1998 Apr;85(4):399-403.

35. Katelaris $\mathrm{CH}$, Widmer RP, Lazarus RM. Prevalence of latex allergy in a dental school. Med J Aust. 1996 Jun
$17 ; 164(12): 711-4$

36. Köse S, Mandiracioğlu A, Tatar B, Gül S, Erdem M. Prevalence of latex allergy among healthcare workers in Izmir (Turkey). Cent Eur J Public Health. 2014 Dec;22(4):262-5.

37. Chowdhury MM, Statham BN. Natural rubber latex allergy in a health-care population in Wales. Br J Dermatol. 2003 Apr;148(4):737-40.

38. Gijbels F, Jacobs R, Princen K, Nackaerts O, Debruyne F. Potential occupational health problems for dentists in Flanders, Belgium. Clin Oral Investig. 2006 Mar;10(1):816. Epub 2005 Sep 22.

39. Porter K, Scully C, Theyer Y, Porter S. Occupational injuries to dental personnel. J Dent. 1990 Oct;18(5):25862.

40. Araujo MW, Andreana S. Risk and prevention oftransmission of infectious diseases in dentistry. Quintessence Int. 2002 May;33(5):376-82.

41. Ship II, Miller MF, Ram C. A retrospective study of recurrent herpes labialis (RHL) in a professional population, 1958-1971. Oral Surg Oral Med Oral Pathol. 1977 Nov;44(5):723-30.

42. Scott A, Gawkrodger DJ, Yeoman C, Egner W, van Noort $\mathrm{R}$, Hatton PV, Grummitt J. Adverse reactions to protective gloves used in the dental profession: experience of the UK Adverse ReactionReporting Project. $\mathrm{Br}$ Dent J. 2003 Dec 20;195(12):686-90.

43. Piirilä P, Hodgson U, Estlander T, Keskinen H, Saalo A, Voutilainen R, Kanerva L Occupational respiratory hypersensitivity in dental personnel. Int Arch Occup Environ Health.2002Apr;75(4):209-16. Epub2002Feb 1.

44. Arbeláez MP, Ocampo MC, Montoya J, Jaramillo LM, Giraldo PM, Maldonado A, Cano E, Mejía OA, García LF, García LF. [Evaluation of the tuberculin reaction in health occupation students] . Rev Panam Salud Publica. $2000 \quad$ Oct;8(4):272-9.

45. Oztürk M, Ozeç I, Kiliç E. Utilisation of personal protective equipment in dental practice. Int Dent J. 2003 Aug;53(4):216-9. 